DOI: 10.2478/ausfm-2021-0005

\title{
Voiceless Screams: Pictorialism as Narrative Strategy in Horror Silent Cinema
}

\author{
Delia Enyedi \\ Babeş-Bolyai University (Cluj-Napoca, Romania) \\ E-mail: delia.enyedi@ubbcluj.ro
}

\begin{abstract}
As a complementary condition to narrative, the notion of pictorialism in film is rooted in the first decades of the medium. In their quest to demonstrate the capturing and restoring of images with various devices, early filmmakers selected views with pictorial qualities in the long-standing tradition of painting, transferring them on film in the form of non-narrative shots. The evolution of fictional narratives in silent cinema displaced the source of inspiration in theatre, assimilating its nineteenth-century tradition of pictorialism. Thus, the film audiences' appeal for visual pleasure was elevated with balanced elements of composition, framing and acting that resulted in pictorially represented moments actively engaged in the narrative system. The paper explores the notion of "pictorial spirit” (Valkola 2016) in relation to that of "monstration" (Gaudreault 2009) aiming to describe the narrative mechanism of provoking fear by means of pictorially constructed cinematic images in a selection of short-length horror silent films belonging to the transitional era, consisting in The Haunted House/The Witch House (La Maison ensorcelée/La casa encantada, Segundo de Chomón, 1908), Frankenstein (J. Searle Dawley, 1910) and the surviving fragments of The Portrait (Пopmpem, Vladislav Starevich, 1915). ${ }^{1}$
\end{abstract}

Keywords: silent cinema, transitional era, horror genre, pictorialism, narration, monstration.

The development of the horror genre in cinema has determined debates over its foundational works. Most historians have linked the first horror films to the early sound era. While containing frightful entities or terrifying scenes, titles belonging to the silent era have been dismissed as inspiration for what was to come. They were categorized as "a series of unrelated attempts at dealing with [...] nineteenth-century literary sources” (Newman 1996, 12) such as Mary Shelley or Edgar Allan Poe. On

1 This work was supported by a grant of the Ministry of National Education, UEFISCDI Romania, project number PN-III-P1-1.1-TE-2016-0067, contract number 135/2018, with the title Iconography of Witchcraft, an Anthropological Approach: Cinema, Theatre, Visual Arts. 
this note, even cult film The Cabinet of Dr. Caligari (Das Cabinet des Dr. Caligari, Robert Wiener, 1920) was considered to have represented "a style and a vision," while Frankenstein (James Whale, 1931) "represents a formula, and the beginnings of a genre" (Hardy 1985, ix). The latter also seems to have been the first horror film to be referred to as such (Kinnard 2000, 1).

However, in the words of Noël Carroll, ultimately "horror films are designed to provoke fear" (1999, 38). Regardless of the critical response they received in the era or the subsequent integration in an evolutionary classification of film genres, horror films are defined by the emotion they generate in the audience, namely fear. Since this emotion can also be provoked by various dystopic cinematic narratives, such as those depicting time travel, defining horror film implies an additional element to fear and that is disgust. They usually revolve around a harmful monster character hostile to the protagonist, threatening to destabilize the established diegetic coordinates of normality by certain supernatural capacities or advantages. In doing so, they provoke not only fear, but also disgust. For the spectator, the prospect of a hypothetical physical interaction with the monster becomes not only fearful, but also repelling (Carroll 1999, 39-40).

In the specific case of horror silent films, inherent characteristics intensified this process of reception. Seemingly immured in quiescence and deepened in black and white footage, they were in fact vibrant by means of live music and, sometimes, by tinted film stock. Discussing the role of their live music accompaniment as a substitute for human vocal expression, Theodor W. Adorno and Hanns Eisler associated its effect to the ghostly impression of the shadow plays, with the role "to exorcise fear or help the spectator absorb the shock" $(1947,75)$. And while the standardized use of colour in cinema is linked to Becky Sharp (Rouben Mamoulian, 1935), as the first feature film to use the three-strip Technicolor technology throughout, an estimated two-thirds of surviving nitrate prints made approximately between 1908-1925 present evidence of tinting, excluding the ones with only tinted intertitles (Cherchi Usai 2019, 49). The remarkable expressive results of this colouring practice can be observed in their punctuation of dramatic situations.

On this introductory note, the three titles selected for analysis, The Haunted House/ The Witch House (La Maison Ensorcelée/La casa encantada, Segundo de Chomón, 1908), Frankenstein (J. Searle Dawley, 1910) and The Portrait (Порmpem, Vladislav Starevich, 1915), share as common denominator the eliciting of a particular emotional response by means of pictorially constructed portrayals of their antagonists actively conducting the narrative. It is relevant to note the fact that from the very start they delineate themselves from seemingly similar films such as The Haunted Castle (Le 
Manoir du diable, Georges Méliès, 1896) or The Haunted Curiosity Shop (Walter R. Booth, 1901). These two titles mirror the appeal of early spectators for witnessing an exhibition of tricks enhanced by the technical possibilities of the recording camera in the hands of Booth or Méliès, both having had careers as illusionists before becoming film directors. In the words of the latter, they fell under the category of "fantastic views," a collocation proposed by Méliès as the creator of this field, replacing the then more frequently used category of "transformation views" (2001 [1907], 140-141). While the French director credited the wide range of procedures behind creating intriguing visual compositions with being "capable of driving the most fearless person mad" (2001 [1907], 140), it did so by exerting the aesthetic of astonishment (Gunning 2009 [1989]) specific to the cinema of attractions (Gunning 2000 [1985]). In other words, these films triggered amazement to the display of the moving pictures technology being demonstrated, often with spectacular results, in front of audiences initiated in the parameters of the performance they were about to witness.

Unlike these two early films, The Haunted House, Frankenstein and The Portrait belong to the transitional era of cinema that extended approximately from 1906/1907 up to 1917. Seeking to explore both aesthetic and narrative developments in the transition to features, filmmakers of the transitional era approached film narrative in relation to nineteenth-century play construction. This becomes a significant aspect as it brings into discussion the dominance of stage melodrama defined by "an overabundance of <action>" (Brewster and Jacobs 2003, 19), a description aiming to reflect the succession of recognitions and reversals in the plots specific to this genre, a succession that can also be extended to horror genre. Thus, the dialectical relation that started to be gradually built between the stylistic system and a narrative one was supported by the construction of the mise-en-scène. More precisely, the tableau was adopted in film composition, understood in one of its several theatrical definitions as a deliberate placement of characters in a scene with the scope of producing a certain effect on the spectators. It became a mode of addressing the public by stylistically signalling the noteworthy narrative "situations" of the plot.

\section{The Witch, the Monster and the Frame in Between}

In a chronology that extends over the first two decades of film production in the twentieth century, the first out of the three films about to be discussed, The Haunted House/The Witch House brings into discussion the contradiction between early cinema and narration. Establishing the moment when one-shot films ceased to embody "an aesthetic of the moving photograph" (Gaudreault 2009, 12) can 
be difficult. With periods overlapping, the transition to multiple-shot films was gradual. But film production in the early 1910s achieved a pivotal moment when filmmakers started shooting with the stage of editing in mind. Shots were required to communicate with other shots as parts of a previously planned scene (Gaudreault 2009, 11-18). This mutation has a significant impact as film narration, in the broad traditional sense of narrative art, came into being. The inquiry of early filmmakers into the narrative possibilities of what thus became cinema found inspiration in literary sources for material to be adapted on screen and in theatre for the composition guidelines to do so. But as André Gaudreault underlines, textual narrative differs dramatically from staged narrative and subsequently from film narrative.

He argues that image operates on two albeit interwoven levels, one of the showing of an image, reflecting mimesis, and one of reconfiguring it through editing, reflecting a non-mimetic form of diegesis. In consequence, he proposes the term monstration for what precedes narration, on the model of image preceding editing (Gaudreault 2009). This operation enables an understanding of the simultaneous functions of the image in narrative films. By editing, individual frames are articulated together into narrative units, with direct implications in the alteration of temporal frame. Thus, unfolding events may be perceived as occurring in the past.

In contrast, monstration is defined as "a mode of communicating a story, which consists of showing characters [...] who act out rather than tell" (Gaudreault 2009, 69). There is a sense of presence linked to monstration, an aspect of significant importance in horror silent films that appeals to mimetic diegesis, depicting action through the gestures, poses and movement of the actors. In de Chomón's film, three characters find refuge from the storm in a house hidden in the woods, a narrative pretext to encompass their exposure to a series of supernatural experiences. The alternative translation of the title, The Witch House reflects the "enchanted" sense of the terms "ensorcelée" or "encantada" from the French and Spanish versions. Therefore, the two men and the woman find themselves under the power of a witch exerting her spells in an enlivened house. They experience objects moving around untouched, defying gravity or disappearing, the appearance of a spectral entity, all culminating with the atypical portrayed witch kidnapping them during their sleep. Combining the pale complexion and the fragile silhouette of a vampire with the sharp long claws and wide teeth of a human-eating monster, the longhaired creature wears what seems to be an attire suited for a female figure. It represents perhaps one of the most overlooked figures of a witch in the history of silent cinema.

The mise-en-scène solution of introducing this character through a painting hanging on the wall of the house is similar to that used in The Portrait, an adaptation 
of Nikolai Gogol's short story The Mysterious Portrait. The longest surviving sequence of this film also includes a painting as a key element in the composition of the frame. The nightmarish core of the visual plot consists in a lifelike portrait gradually altering its appearance before eventually coming to life under the horrorstricken eyes of the protagonist. Gogol's text gives insight into this menacing figure as inciting a moral dilemma for a young painter, rather than attempting on his physical wellbeing. Nevertheless, its disturbing portrayal is created by appealing to Gothic aesthetics, signalling the pioneering of the Gothic silent cinema by de Chomón (Aldana Reyes 2017, 186).

In folk tales, the frame, more specifically that of a mirror, has long been associated with being a portal to the after-life. In these two films, the hanging pictures allow the antagonists to break their delineating limits and to even walk off, triggering the eerie suspension of normality characteristic to horror films. But on the level of the visual composition, they also carry the function later obtained in cinema through reframing, as seen in The Portrait. With their silhouettes being cut from the chest up, the menacing entities approach the characters as well as the audience, a substitute for the effect obtained through a medium shot. In this way, the characters' reaction to supernatural occurrences and the repulsion to their appearances manifested by the spectators is accentuated by the mise-en-scène in which the standard framing of the era enclosed the entire bodies of the actors. Their poses and gestures are choreographed in accordance with the screen time allotted to the antagonists. When the witch occupies the frame of the painting, signalling itself as an inciting element of the plot, the three friends avoid engaging with it by moving to the sides of the screen frame [Fig. 1-2]. In the claustrophobic space of his apartment, the young painter recedes from the menacing painting in the securing space of his bed, partially visible in one side of the frame.

Clearing the centre of visual attention to the advantage of one or the other character provides the required space for physical reactions. Horrified, the visitors of the house in the forest slip and fall, resorting to wide, dynamic gestures of anxiety. Since "posing was keyed to genre and situations, and effectively coexisted with other, more fluid, uses of gesture" (Brewster and Jacobs 2003, 106), this histrionic style of acting is no longer considered a precursor of the realistic acting style. Instead, it is an evidence of how film technology influenced styles and nuances of acting. This is more evident in the The Portrait, having been produced seven years after The Haunted House, in the way the protagonist benefits from the reduction of the framing to the advantage of pantomime in order to externalize his fear. 
In a similar medium close-up framing, the monster in Frankestein assumes a central position in the composition of a key scene of the film. The earliest known screen version of Mary Shelley's canonical Gothic novel, it was labelled as a liberal adaptation. J. Searle Dawley's interpretation of the original plot envisions the monster as a projection of Frankenstein's most tenebrous thoughts, fading away in a mirrored reflection as the young medical student's mind is purified by the love for his bride. At one significant narrative moment, the confrontation of the monster with its reflection in the mirror leaves it appalled by the horrific appearance before his eyes. Interestingly enough, the Edison Company released a statement at the time of the premiere saying that "wherever, therefore, the film differs from the original story, it is purely with the idea of eliminating what would be repulsive to a moving picture audience” (Edison Bulletins 1910, 12).

In an apparent contradiction, this promotional articlealso took pride in announcing "some of the most remarkable photographic effects that have yet been attempted" in the scene depicting the "hideous" monster coming to life, "probably the most weird, mystifying and fascinating scene ever shown on a film” (Edison Bulletins 1910, 12). The result rose to the expectations, as the scene was accomplished by reversing the footage of a dummy being set on fire to give the impression of a body rising from nothingness. The shades casted by the flames accentuate mechanically manipulated movement, resulting in an impressive synaesthesia between the infernal cauldron and the artificial soul it gave rise to [Fig. 3].

The development of horror silent cinema depended on such types of filmic solutions related to composition or reframing in order to reduce the distance between repelling characters and the audience. Additional frames in the form of pictures added in the background, embedded in the narrative, oriented the gaze of the spectators to the witch in The Haunted House or the enlivened subject of the painting in The Portrait. Furthermore, compositions depleted of additional miseen-scène elements, such as the creation of the monster in Frankenstein, supported even more deepened focus, up to the extreme imagery of the genesis of a monster. These specific scenes extracted as individual visual stances support a mimetic interpretation within the monstration paradigm. By means of diverse acting styles, they conveyed disgust through the physical action of the antagonists and fear through the physical reaction to it by the protagonists. Reintegrating them into the cinematic context they belong to exposes a pictorial complicity they develop with narration. 


\section{Pictorial Geometries of Fear}

The appeal of early silent film audiences for visual pleasure seems to have been primarily tied to the "actor's assumption of poses and attitudes" which "was much more important and was important for far longer" than previously believed (Brewster and Jacobs 2003, 81). Stemming from the emphasis put on this mimetic conveying of the narrative in silent cinema, longer shots and in-depth composition were gradually developed in order to support it. Discussing the elements required to give force to the formal qualities of cinematic composition in contemporary cinema, Jarmo Valkola identifies movement, simple and slowly integrated, and an emphasis put on the grouping of the actors, differentiated from the surroundings, with light and perspective used to articulate the spatial component of the narrative $(2016,20)$.

Rooted in photography, pictorial stillness in moving images can be obtained by the freezing of an image, while also maintaining its connection with the rest. But strengthening the expressive meaning of a scene can also be implied through the immobility of the character, as in the case of the creation of the monster in Frankenstein. Reduced movement signals a gruesome process of coming to life, but it is the duration of the scene that gives sense of burdensome weight being inflicted on a body trying to detach from the partially visible cauldron. Expressive pictorial composition is fulfilled by balancing the dominating dynamics of the dummy with the fire, as flames and ashes fill the sultry surrounding space, later echoed in the lingering haunting the monster will exert on his creator as the structuring narrative element.

In a different approach, the opening scene of The Haunted House creates depth of field by means of mise-en-scène. A diagonal line in the form of a path separates the deep forest in the background and the lake in the foreground. Walking along it, the group movement of the characters expresses the search for a shelter from the storm. The next scene reveals it to be a house hidden in the forest. But before the lightning descending from heavy clouds of storm share with the audience the unusual human features of the building in the following scene, this road taken by the three friends signals a rite of passage. Through its function of delineating the space of the visual composition, the forest scenery and its reflection on the surface of the lake are of about equal proportion, foreshadowing the narrative reversal of natural laws.

While in the space of the house, an open door in the background gives little hope of escape for the three protagonists already aware of being entangled in a forest fallen under the spells of a witch. Claustration imprinted to a composition of an interior space is suggested to a larger degree in The Portrait. The narrative conveys a more intimate depth of field, as an easel and the board of a bed indicate little 
distance between these objects and the portrait hung in the background. The easel undertakes a metaphorical function in the overall narrative by facing the painting, obscuring the divisive possibilities art may imply. The bed, on the other hand, is oriented towards the audience, with its board as a robust physical obstruction in the face of menace [Fig. 4]. The young painter constantly repeats the movement of lying in it and then rising from it as a response to his fear. The process of identification of the spectator with the protagonist reaches its most intense level with the support of this element of mise-en-scène by exerting the disquieting effect of a personal secured space associated with the vulnerability of the humans' sleeping stages. This specific narrative trigger is also present in The Haunted House and Frankenstein with all protagonists physically interacting with the witch or the monster while lying in their beds.

\section{Horror and the Pictorial Spirit}

In the case of the cinematic experience, interpreting the gestures and movement of the actors as integral elements in complex visual compositions is fundamental in identifying the narrative function of pictorialism in silent films. Acting, together with mise-en-scène, depth of field or framing become complementary instruments in creating pictorial moments potentiated by applied or implied stillness, often stressed by its duration. The ensemble of these compositional elements visually stresses associations and connotations which actively shape both the cinematic narration and its reception. They generate "the 'pictorial spirit' of the spectator's imagination" (Valkola 2016, 22) as a strategy of mental punctuation of the filmic narrative through pictorial image.

While this type of confrontational relation between audience and film is usually restrained to discussing the cinema of attractions, André Gaudreault successfully demonstrates the capacity of the kinematic image to contain a monstrative imprint while simultaneously remaining conjunct to the overall narrative. Individual image is seen as capable to sustain visual autonomy as a scene. In specifically discussing horror silent cinema, the dominance of the system of monstrative attractions can be traced along two of its defining aspects. It demanded an escalating level of spectacle, while a minimum level of narrative coherence was needed to deliver intelligible spectacular-oriented content (Phillips 2018, 45-46). While not an early film, The Haunted House implemented a minimal narrative constructed by means of pictorialism, proposing a visual approach of attractional descent that develops over the course of almost the entire film, ultimately leading to an open ending. 
Frankenstein and The Portrait, while being literary adaptations, resorted to pictorial compositions due to their attractional function that supported the irrational nature of the depicted horror.

Correlating pictorialism to monstration determines a mutual enhancement of two concepts. This operation enables an understanding of transitional cinema as bearing the weight of its own dominant visual regime while undergoing a process of narrative integration. Despite joining other narrative arts, the intrinsic nature of it lies in exploring the possibilities of the visual composition, primarily by means of mise-en-scène. Equally indebted to photography and theatre, pictorialism becomes an instrument, on the level of both the composition and reception, in the process of monstration. The response of the audience is a significant matter in this equation when further reducing the discussion to horror silent cinema. Titles belonging to this category stress an "exhibitionist confrontation" between the image and the spectator, if we are to borrow Tom Gunning's terminology describing the specificities of the cinema of attractions $(2000,232)$, seen as perfected types of nineteenth-century fairground entertainment. This choice is by no means aleatory, as the absence of synchronized sound in horror silent films enhanced visual shocks. In their quest to elicit fear and disgust, pictorial compositions aimed to give voice, even if only among the members of the audience, to otherwise silent screams.

\section{References}

Adorno, Theodor W. and Hanns Eisler. 1947. Composing for the Films. London: Dennis Dobson.

Aldana Reyes, Xavier. 2017. Spanish Gothic. National Identity, Collaboration and Cultural Adaptation. London: Palgrave Macmillan.

Brewster, Ben and Lea Jacobs. 2003 [1997]. Theatre to Cinema. Stage Pictorialism and the Early Feature Film. Oxford: Oxford University Press.

Carroll, Noël. 1999. Film, Emotion, and Genre. In Passionate Views. Film, Cognition, and Emotion, eds. Carl Plantinga and Greg M. Smith, 21-47. Baltimore \& London: Johns Hopkins University Press.

Cherchi Usai, Paolo. 2019. Silent Cinema. A Guide to Study, Research and Curatorship. London: BFI/ Bloomsbury.

Gaudreault, André. 2009. From Plato to Lumière. Narration and Monstration in Literature and Cinema. Toronto, Buffalo, London: University of Toronto Press. 
Gunning, Tom. 2000 [1985]. The Cinema of Attraction: Early Film, Its Spectator, and the Avant Garde. In Film and Theory: An Anthology, eds. Robert Stam and Toby Miller, 229-235. Oxford: Blackwell Publishers.

Gunning, Tom. 2009 [1989]. An Aesthetic of Astonishment: Early Film and the (In) credulous Spectator. In Film Theory and Criticism: Introductory Readings, eds. Leo Braudy and Marshall Cohen, 736-750. New York: Oxford University Press. Hardy, Phil, ed. 1985. Horror. The Aurum Film Encyclopedia. London: Aurum.

Kinnard, Roy. 2000. Horror in Silent Films: A Filmography, 1896-1929. Jefferson, NC, United States: McFarland \& Co Inc.

Méliès, Georges. 2011 [1907]. Kinematographic Views. In Film and Attraction. From Kinematography to Cinema, André Gaudreault, 133-152. Urbana, Chicago and Springfield: University of Illinois Press.

Newman, Kim. 1996. The BFI Companion to Horror. London: BFI Publishing/ Cassell.

Phillips, Kendall R. 2018. A Place of Darkness. The Rhetoric of Horror in Early American Cinema. Austin: University of Texas Press.

Valkola, Jarmo. 2016. Pictorialism in Cinema. Creating New Narrative Challenges.

Newcastle upon Tyne: Cambridge Scholars Publishing.

***. 1910. Edison Bulletins. The Film Index vol. 5, no. 12 (March): 12.

\section{List of Figures}

Figures 1-2. In The Haunted House (1908) the witch delineated by the frame of the painting and the characters as a group alternately occupy the frame in an action reaction display of histrionic gestures and poses.
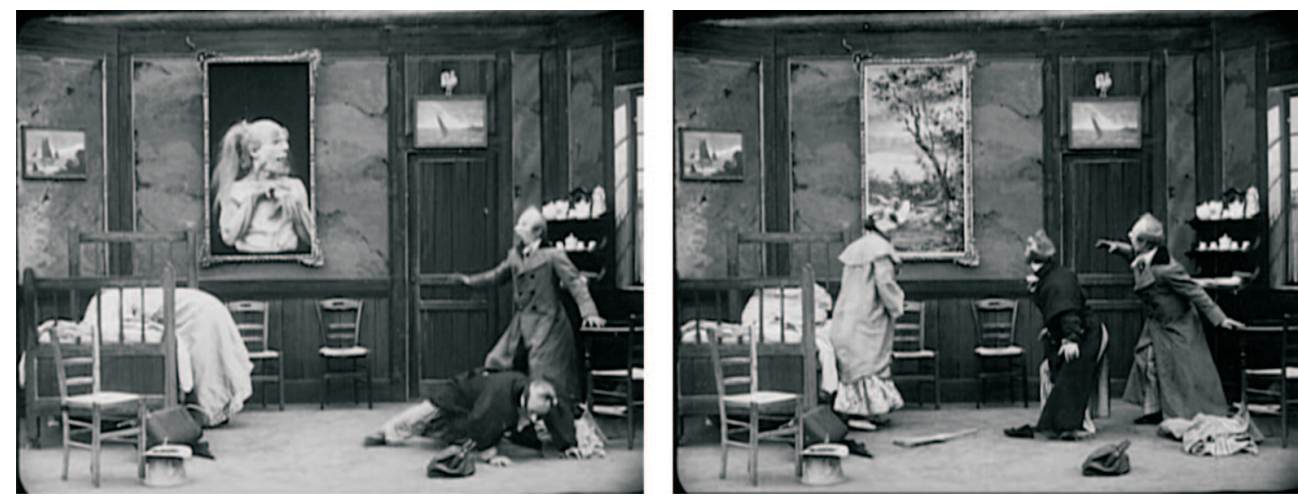
Figure 3. Pictorial stillness conveyed by means of reduced movement of the monster in Frankenstein (1910) during the scene of its creation. Figure 4. Elements of miseen-scène, depth of field and acting pictorially punctuate the filmic narrative in The Portrait (1915).
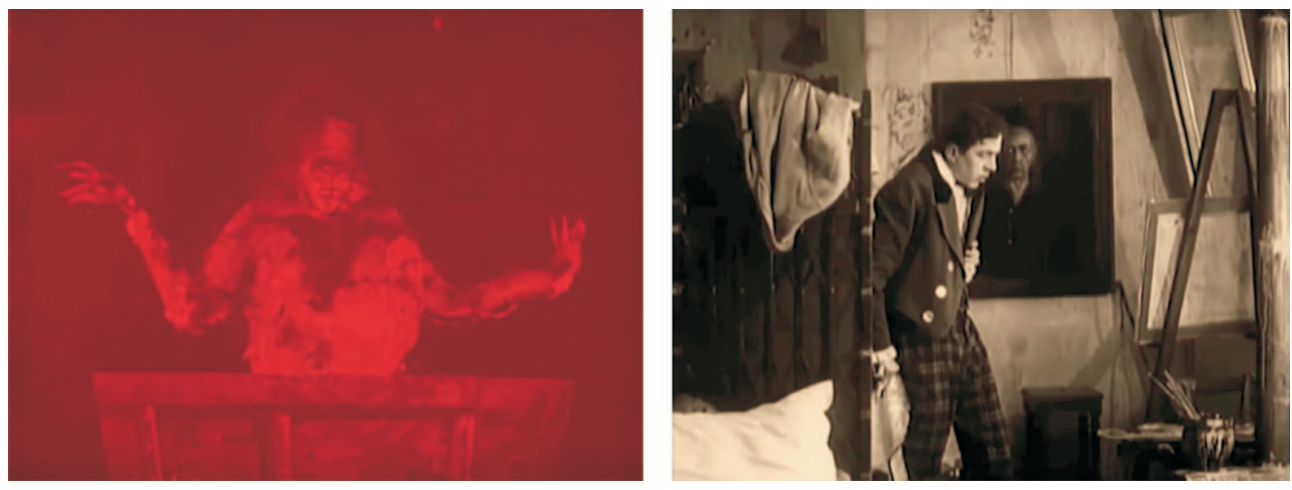